Cad.Est.Ling., Campinas, (40):17-27, Jan./Jun. 2001

\title{
RESTRIÇÕES GRADIENTES SOBRE RELAÇÕES ENTRE VOGAIS PRÉ-TÔNICAS E TÔNICAS NO LÉXICO DO PORTUGUÊS BRASILEIRO ${ }^{1}$
}

\author{
ELEONORA CAVALCANTE ALBANO ${ }^{2}$ \\ (LAFAPE ${ }^{3}$-IEL-UNICAMP)
}

This paper contends that the two competing "rules" that the literature on Portuguese morphophonology has claimed to apply to the verb paradigm, namely, vowel height harmony and vowel lowering, are, in fact, phonotactic restrictions that apply, in a categorical fashion, to the inflected verb stem and, in a gradient fashion, to the non-inflected verb stem. At least in Brazilian Portuguese, the non-inflected verb stem is consistent with the inflected verb stem in that lowering predominates in both in the first conjugation and harmony predominates in both in the second and third conjugation. Lowering is in turn consistent with other versions of $O C P$ which cut across all grammatical categories. The findings are interpreted in light of Acoustic-Articulatory Phonology (Albano 2001), which predicts, on grounds of facilitation of decoding of acoustic-to-articulatory relations, that stress tends to attract low vowels except where vowel quality is otherwise predictable.

\section{INTRODUÇÃO}

Sabe-se que as línguas flexionais marcam as classes morfossintáticas através de afixos. As classes de afixos podem, por sua vez, ser identificadas por restrições fonotáticas. Pesquisas recentes (Pierrehumbert 1993, Frisch 1996) mostram, além disso, que algumas dessas restrições são melhor entendidas não como categóricas e atreladas a ambientes fixos, mas como probabilísticas e direcionais.

Este trabalho apresenta uma análise estatística das vogais lexicais do português que reinterpreta o processo de flexão verbal tradicionalmente conhecido como "metafonia" (Cavacas 1920) e rebatizado "harmonia" pela literatura gerativa (Harris 1974, Mateus 1975) como parte de uma restrição fonotática gradiente, que se aplica da direita para a esquerda, fazendo vogais tenderem a concordar entre si quanto à altura. Essa restrição interage com outra, também gradiente, mas aplicável da esquerda para a direita, que faz com que vogais acentuadas tendam a ser baixas, independentemente de condicionamento morfológico.

${ }^{1}$ Nova versão, substancialmente revista, de parte do Capítulo 6 de Albano (2001). Agradecemos à Editora Mercado de Letras (www.mercado-de-letras.com.br) a permissão para reproduzir as partes do texto que foram mantidas.

${ }^{2}$ Bolsista de Produtividade em Pesquisa do CNPq.

${ }^{3}$ Laboratório de Fonética e Psicolingüística do IEL-UNICAMP. A pesquisa no LAFAPE tem sido significativamente financiada pelo CNPq e pela FAPESP. 
Os dados consistem nos 27.024 verbetes de Ferreira (1977), dos quais 4.744 são infinitivos verbais. A ferramenta utilizada foi o programa Listas, de autoria da equipe do LAFAPE, que permite selecionar palavras por terminação, assim como pela presença de determinadas seqüências de caracteres. Foram analisadas as relações entre vogais, independentemente das consoantes intervenientes, em verbos e não-verbos. As formas em hiato foram excluídas.

\section{METODOLOGIA: A RAZÃO O/E}

A metodologia de análise baseia-se numa sugestão de Greenberg (1950), retomada, desenvolvida e refinada por Pierrehumbert (1993, 1994) e Frisch (1996), segundo a qual o léxico pode ser encarado como um conjunto de distribuições nãoaleatórias de probabilidades não só de ocorrência mas também de combinação de unidades fônicas. Daí decorre que a gramática fônica não é mais do que o conjunto desses vieses lexicais, que exprimem ora a atração, ora a repulsão da língua por certas unidades ou conjuntos delas.

A método de Greenberg é bastante simples e satisfaz a um primeiro nível de descrição dos fatos. Trata-se de levantar as freqüências de ocorrência de unidades e/ou combinações de interesse, em corpora representativos da língua, e exprimir os seus desvios da aleatoriedade como uma razão entre as freqüências efetivamente observadas e as que seriam esperadas $(\mathrm{O} / \mathrm{E})$ caso as unidades fossem, de fato, distribuídas ao acaso - no caso mais simples, equiprováveis - nos seus contextos de ocorrência. Veremos, nas seções que seguem, que esse procedimento ilumina o inventário dos segmentos possíveis no português brasileiro (doravante, PB), assim como as suas principais tendências combinatórias.

Pierrehumbert e colaboradores acrescentam a essa descrição um nível superior, no qual a variação da razão O/E para cada fenômeno de interesse é expressa através de uma função logística. Uma tal função é a expressão formal de uma restrição de boa formação com probabilidade entre 0 e 1 . Restrições categóricas teriam limites precisos. Restrições gradientes - isto é, de aplicação probabilística - teriam limites vagos (no sentido preciso do inglês fuzzy).

Não nos deteremos aqui nesse segundo aspecto, o de formalização matemática, da teoria, pois as questões empíricas a resolver ainda são muitas e, como veremos adiante, bastante delicadas. Mais importante, no momento, é mostrar que a aplicação sistemática da metodologia de Greenberg a uma língua produz resultados reveladores que não se deve ter pressa em modelar. Antes, é preciso estabelecer, com o levantamento maciço de dados fonotáticos, que o preferido e o evitado por qualquer língua, longe de serem arbitrários, seguem uma lógica decorrente da combinação de acidentes históricos com a necessidade de coordenar gestos fônicos num espaço acústico-articulatório.

Os primeiros passos para um estudo fônico probabilístico do PB foram dados por Albano, Moreira, Aquino, Silva e Kakinohana (1995), ainda sem familiaridade com a literatura ora citada. Trata-se de um levantamento da frequiência de ocorrência de unidades segmentais tradicionais diferenciadas quanto à posição silábica (ataque, 
núcleo e coda). Os corpora examinados foram o MiniDicionário Aurélio e 57 gravações do Projeto NURC, tendo as transcrições ortográficas, disponíveis sob forma digital, sido convertidas numa transcrição fonética larga com o auxílio de um conversor ortográfico-fônico (Albano e Moreira 1996). Os resultados, mesmo expressos em simples termos percentuais, revelaram um padrão de preferências que aponta claramente para uma lógica acústico-articulatória.

A natureza ao mesmo tempo acústica e articulatória do espaço fônico explorado pelo PB fica clara quando se examinam as suas preferências segmentais. Em certas posições, são evitados segmentos em que um gesto articulatório mascara outro, favorecendo-se aqueles que melhor evidenciam os contrastes acústico-auditivos. Já, em outras posições, o que se favorece é a fluência, tendo preferência os gestos mais deslizáveis, isto é, mais capazes de sobrepor-se a outros.

Quanto às combinações de segmentos, o léxico do PB manifesta também um sugestivo concurso de tendências à economia articulatória e à saliência auditiva. $\mathrm{O}$ sistema vocálico apresenta, em alguns setores do vocabulário, uma tendência à harmonia semelhante àquela que se morfologizou no sistema verbal e, em parte, também na flexão de gênero (por exemplo, 'novo/nova'). Já, em outros setores, a harmonia é evitada, o que acontece também no sistema consonantal, onde só as posições adjacentes (i. e., os encontros tauto e heterossilábicos) tendem à homorganicidade. As seqüências de consoantes com vogais intercaladas atestam uma versão probabilística daquilo que é conhecido na literatura fonológica como "princípio do contorno obrigatório" (Leben 1973) - obligatory contour principle, abreviado OCP, i. e., a tendência a evitar a repetição seqüencial das mesmas propriedades fônicas.

Embora não haja aqui espaço para tratar das restrições consonantais, é interessante assinalar que os sistemas consonantal e vocálico são regidos por princípios de combinação diferentes, em consonância com as suas respectivas taxas de informação. Em outras palavras, as consoantes, que são mais informativas, tendem a contrastar e as vogais, que são mais redundantes, tendem a serem previsíveis através das restrições fonotáticas probabilísticas em que, como se verá abaixo, os princípios da harmonia e do OCP competem entre si.

\section{O ABAIXAMENTO NO ÂMBITO DA RELAÇÃO ENTRE ACENTO E QUALIDADE VOCÁLICA}

Uma análise da frequiência relativa das vogais no MiniDicionário Aurélio revela que não apenas a altura, mas também posição da língua está correlacionada à acentuabilidade. A Tabela 1 apresenta as freqüências relativas das vogais desse corpus dividindo-as entre plenas (as pré-tônicas e tônicas) e reduzidas (as pós-tônicas [I, $\mathfrak{e}, \boldsymbol{U}]$ ). Há, além disso, entre as vogais plenas, uma distinção entre a última (i. e., a tônica), de acentuação provável, conforme a prosódia da frase, e as demais (pré-tônicas), que, às vezes, recebem o chamado acento secundário, o qual deve, contudo, ser visto como facultativo e gradiente, conforme mostrou Gama Rossi (1998). 


\begin{tabular}{|l|c|l|c|l|l|}
\hline \multicolumn{5}{|c|}{ Vogais do Minidicionário Aurélio } \\
\hline & O/E & \multicolumn{2}{|l|}{ O/E } & \multicolumn{2}{l|}{ O/E } \\
\hline 'a & 3,17 & i & 1,19 & I & 0,50 \\
\hline a & 1,46 & 'i & 1,16 & 'E & 0,37 \\
\hline u & 1,27 & 'e & 1,02 & u & 0,37 \\
\hline e & 1,25 & o & 0,73 & 'u & 0,34 \\
\hline e & 1,23 & 'o & 0,62 & 'o & 0,33 \\
\hline
\end{tabular}

Figura 1 - Freqüência relativa de vogais plenas, tendendo à acentuação (tônicas) ou não (prétônicas), e reduzidas (pós-tônicas) no MiniDicionário Aurélio.

As vogais centrais $[a, \mathfrak{e}]$ são, sem dúvida, as grandes favoritas do dicionário, alcançando $\mathrm{O} / \mathrm{E}>1 \mathrm{em}$ todas as posições. A razão O/E não é, entretanto, a mesma em todos os casos: é, conforme esperado, diretamente proporcional à acentuabilidade, atingindo um valor extremamente alto na posição mais acentuável. Já para as vogais arredondadas, essa relação se inverte. A razão $\mathrm{O} / \mathrm{E}$ é inversamente proporcional à acentuabilidade, tanto para as vogais do tipo [o] como para as do tipo [u], sendo que apenas a reduzida $[\mathrm{U}]$ alcança $\mathrm{O} / \mathrm{E}>1$. As anteriores do tipo [e] e [i] constituem, por sua vez, um caso intermediário: $\mathrm{O} / \mathrm{E}$ é muito baixo na posição reduzida e alcança valores maiores que 1 nas posições plenas, sendo que a maior vantagem ocorre na menos e não na mais acentuável.

Esses dados sugerem que a posição mais acentuável prefere as vogais baixas, tendo atraído as vogais inovadoras $\left[\varepsilon\right.$, o] ao longo da história do português ${ }^{4}$. Isso é coerente com o fato de o acento preferir, também, vogais de maior energia, evitando, por isso, as posteriores. As mesmas preferências manifestam-se, em menor grau, nas demais posições plenas, coerentemente com a hipótese de Gama Rossi sobre a gradiência do acento secundário.

Daí decorre que o caso particular de OCP que podemos chamar de abaixamento, isto é, a restrição que faz com que a vogal acentuada tenda a ser baixa ou mais baixa que as átonas precedentes é, como veremos abaixo, extremamente geral, embora se acentue nas formas verbais flexionadas, tornando-se categórica (i. e., com probabilidade próxima de 1) quando o acento recai sobre uma vogal média, em formas tais como 'leva', 'pega', 'mora', etc. Note-se, a propósito, que as vogais médias são as únicas a oferecer a opção entre as categorias baixa e não-baixa.

${ }^{4}$ Alguns $[\varepsilon$, o] derivam-se diretamente de vogais breves do Latim. A maioria, entretanto, foi introduzida por processos morfológicos próprios do português. 


\section{HARMONIA E OCP EM VOGAIS DE VERBOS E NÃO-VERBOS}

A tendência, acima documentada, a preferir vogais baixas e anteriores não-altas nas posições acentuáveis da palavra prevê que certas combinações $\mathrm{V}-\mathrm{V}$ estejam bem representadas no PB. Seqüências de vogais idênticas tais como [a, a] e [e, e], assim como sequiências de baixas com anteriores não-altas (e.g., [a, e], [e, a]), são coerentes com essa tendência. Torna-se, então, oportuno indagar se há vieses combinatórios numa ou noutra direção e se esses têm relações, por um lado, com a preferência do acento pelas vogais baixas, e, de outro, com a harmonia vocálica morfologizada na história do português.

Em Albano (2001, pp. 200-206), essa hipótese foi investigada com as ferramentas então disponíveis, que levaram a uma redução considerável do corpus. Para tanto, o número de sílabas foi usado como critério de seleção automática, no dicionário, de um subconjunto representativo do vocabulário, a saber: os trissílabos paroxítonos, escolhidos não só pela alta freqüência ( $34 \%$ do corpus), mas também pela forma fixa, que contém apenas duas vogais plenas, o que facilita o cálculo das freqüências esperadas.

Esse critério tem, entretanto, a desvantagem de excluir os verbos, listados no dicionário no infinitivo, que é sempre oxítono. A presente revisão do mesmo estudo superou as limitações técnicas quanto ao tamanho do corpus e considerou todas as palavras que continham pares de vogais pré-tônicas e tônicas intercaladas por uma ou duas consoantes (o que corresponde a $78 \%$ do corpus). A Tabela 2 resume os novos resultados, que incluem, além de substantivos e adjetivos, verbos:

\begin{tabular}{|c|c|c|c|c|c|c|c|}
\hline V-'V & $\mathrm{O} / \mathrm{E}$ & V-'V & $\mathrm{O} / \mathrm{E}$ & V-'V & $\mathrm{O} / \mathrm{E}$ & V-'V & $\mathrm{O} / \mathrm{E}$ \\
\hline a'o & 1.496309 & u'a & 1.190657 & e'i & 1.018192 & i'e & 0.946129 \\
\hline o'i & 1.321775 & $a^{\prime} u$ & 1.136964 & e's & 1.010037 & e'a & 0.939085 \\
\hline $\mathrm{o}^{\prime} \varepsilon$ & 1.27664 & $a^{\prime} \varepsilon$ & 1.113055 & $a^{\prime}$ & 1.003728 & o'a & 0.93035 \\
\hline i'a & 1.259091 & e'u & 1.101221 & a'e & 0.99191 & $a^{\prime} a$ & 0.872407 \\
\hline u'u & 1.254658 & u'i & 1.072247 & o'e & 0.986575 & o'u & 0.856876 \\
\hline o'o & 1.243944 & i's & 1.040917 & e'o & 0.967813 & $e^{\prime} \varepsilon$ & 0.847659 \\
\hline e'e & 1.191275 & a'i & 1.038762 & $i^{\prime} \varepsilon$ & 0.947717 & u'o & 0.804381 \\
\hline
\end{tabular}

Tabela 2 - Freqüência relativa de combinações de vogais pré-tônicas e tônicas intercaladas por uma ou duas consoantes no MiniDicionário Aurélio.

$\mathrm{O}$ estudo anterior seguira a literatura em calcular a freqüência esperada como a média das frequiências observadas, respeitados os diferentes tamanhos do inventário das duas posições (i.e., o total da posição dividido pelo número de vogais possíveis na outra posição).

Este estudo baseou-se no raciocínio de que os desvios da eqüiprobabilidade refletem os vieses das vogais isoladas e alterou essa metodologia. A frequiencia esperada foi estimada com base nas probabilidades independentes de cada par. Assim, para calcular a probabilidade do par, multiplicou-se a probabilidade da vogal pré-tônica 
ocorrer nessa posição pela probabilidade da tônica ocorrer nessa posição. Isso neutraliza a influência dos vieses de cada vogal em isolamento.

Além de confirmar as tendências já manifestas nas preferências isoladas, na medida em que muitas das combinações de [a] e [e] alcançam $\mathrm{O} / \mathrm{E}>1$, os novos resultados reiteram o lugar de [i] entre as vogais plenas preferidas do dicionário, conferindo um valor de $\mathrm{O} / \mathrm{E}>1$ a ambas as combinações de [a] e [i]. Confirma-se também a conclusão do estudo anterior de que não há, no conjunto das três classes gramaticais, preferência pela harmonia ou pelo OCP. As combinações de ambos os tipos estão igualmente bem representadas entre aquelas em que $\mathrm{O} / \mathrm{E}>1$.

Essa divisão de trabalho entre as restrições dos dois tipos não é, entretanto, uniforme entre as classes gramaticais mais representativas do léxico do PB. É, antes, uma característica do sistema nominal (63\% do corpus), onde as duas tendências interagem com as relações entre a acentuabilidade e a qualidade vocálica vistas na seção anterior. Os verbos ( $15 \%$ do corpus), como se verá abaixo, comportam-se de outra maneira.

Para expor o argumento, convém, primeiro, subdividir os dados em subconjuntos de substantivos e adjetivos. Isso revela que essas classes são relativamente homogêneas, obtendo-se, aproximadamente, a mesma tendência a alternar entre contorno e harmonia da Tabela 2. Uma certa preferência por combinações em que há um contorno de abertura coerente com o abaixamento, tal como em [o'e], [o'o], [i'a], [i'o] e [u'a], também comparece em ambas as classes, como demonstra a Tabela 3:

\begin{tabular}{|c|c|c|c|}
\hline Subst. & $\mathrm{O} / \mathrm{E}$ & Adj. & $\mathrm{O} / \mathrm{E}$ \\
\hline u'u & 1.920664 & a'o & 1.760865 \\
\hline$o^{\prime} \varepsilon$ & 1.527017 & o's & 1.68163 \\
\hline o'i & 1.443272 & o'u & 1.442575 \\
\hline i'a & 1.304574 & $i^{\prime} \varepsilon$ & 1.264834 \\
\hline a'o & 1.30404 & u'a & 1.257102 \\
\hline e'u & 1.247284 & e'i & 1.212348 \\
\hline e's & 1.211741 & $a^{\prime} u$ & 1.158786 \\
\hline i'o & 1.127145 & i'a & 1.154821 \\
\hline o's & 1.117966 & o'a & 1.130735 \\
\hline i'e & 1.110897 & $o^{\prime} \varepsilon$ & 1.122539 \\
\hline e'o & 1.110616 & i'e & 1.118071 \\
\hline e'i & 1.095348 & i'o & 1.104977 \\
\hline o'e & 1.078349 & $\mathrm{e}^{\prime} \varepsilon$ & 1.103925 \\
\hline u'a & 1.074528 & a'i & 1.103741 \\
\hline $\mathrm{a}^{\prime} \varepsilon$ & 1.00868 & a's & 1.059462 \\
\hline e'e & 1.003018 & e'e & 1.03509 \\
\hline
\end{tabular}

Tabela 3 - Freqüência relativa de combinações de pré-tonicas e tônicas intercaladas por uma ou duas consoantes nos substantivos e adjetivos do MiniDicionário Aurélio. 
Já um exame à parte dos verbos, incluindo entre eles 'pôr' e seus compostos, revela outras tendências combinatórias, apresentadas na Tabela 4 abaixo. Prevalecem as combinações harmônicas, especialmente [e'e, o'o, u'i]. Isso se torna particularmente interessante quando lembramos que a harmonia de altura está morfologizada na flexão verbal (em alternâncias como 's[i]go/s[ع]gue', etc.). Tenderiam, então, os radicais verbais não flexionados a seguir o mesmo princípio de harmonia de altura implementado pela morfologia?

Para responder a essa pergunta, examinou-se todo o conjunto dos verbos do MiniDicionário Aurélio. Cabe notar que essa lista é bastante exaustiva para as conjugações não-produtivas, isto é, a segunda e a terceira, que contêm, respectivamente, 380 e 368 ocorrências. A primeira conjugação, que constitui uma lista aberta, devido à produtividade, também está bem representada, contendo 3895 ocorrências. Assim, os desvios da independência de todos os pares de todas foram estimados, através da razão O/E, e separados para as três conjugações regulares.

Os resultados revelam que os radicais verbais não flexionados tendem a concordar em altura e/ou posição da língua com a marca da conjugação ou vogal temática, exceto na primeira conjugação, conforme mostra a Tabela 4:

\begin{tabular}{lr} 
Verbos & \multicolumn{1}{l}{ O/E } \\
e'e & 2.499014 \\
o'o & 2.374405 \\
u'i & 2.186432 \\
i'a & 1.099786 \\
a'a & 1.066606 \\
a'o & 1.037433 \\
o'e & 1.03714 \\
u'a & 1.001914 \\
e'o & 0.99725
\end{tabular}

Tabela 4 - Freqüência relativa de combinações de pré-tônicas e tônicas intercaladas por consoantes nos verbos do MiniDicionário Aurélio.

$\mathrm{Na}$ Tabela 5, que separa os dados da primeira conjugação, as vogais de final do radical não flexionado têm todas, à exceção de [e], freqüências relativas muito próximas do esperado, o que é consistente com o caráter altamente produtivo do sufixo formador de verbos 'ar'. 


\begin{tabular}{|l|r|}
\hline \multicolumn{2}{|c|}{$1^{\mathrm{a}}$ Conjugação } \\
\hline $\begin{array}{l}\text { Vogal final do radical não } \\
\text { flexionado }\end{array}$ & Razão O/E \\
\hline $\mathrm{i}$ & 1.099786 \\
\hline $\mathrm{a}$ & 1.066606 \\
\hline $\mathrm{u}$ & 1.001914 \\
\hline $\mathrm{o}$ & 1.037433 \\
\hline $\mathrm{e}$ & 0.836156 \\
\hline
\end{tabular}

Tabela 5 - Freqüência relativa da vogal final do radical não flexionado nos verbos da primeira conjugação no MiniDicionário Aurélio.

Parece razoável afirmar que, nas formas flexionadas, a morfologia aproxima a primeira conjugação das suas irmãs menos produtivas, ao tornar harmônicas as formas rizotônicas dos radicais não flexionados em [e] (e.g., 'p[ع]ga', ' $1[\varepsilon]$ va', etc.), que têm $\mathrm{O} / \mathrm{E}>1$. Ressalve-se, porém, que essa harmonia, entre uma vogal plena e uma reduzida, difere da observada nos substantivos e adjetivos, que ocorre entre vogais plenas. Observe-se também que, ao contrário dos outros casos de harmonia morfologizada, não há, na primeira conjugação, competição entre a harmonia e o abaixamento, pois ambos conduzem aos mesmos resultados.

$\mathrm{Na}$ segunda e a terceira conjugações, as restrições harmônicas de altura incorporadas pela morfologia são, ao contrário, coerentes com tendências análogas já manifestadas independentemente no final do radical. Observe-se, na Tabela 6, a absoluta preferência dos radicais não flexionados pelo final [e], que coincide com a marca da conjugação. Isso deve-se, em grande parte, à alta freqüência dos sufixos derivacionais 'ecer' e 'escer', etc., ainda produtivos, mas manifesta-se também em formas monomorfêmicas, tais como 'beber', 'meter', 'receber', etc. É também harmônica, quanto ao grau de constrição, a única vogal que atinge O/E próximo de 1, que é a contraparte posterior do tema em [e], ou seja, [o]:

\begin{tabular}{|l|r|}
\hline \multicolumn{2}{|c|}{$2^{\text {a }}$ Conjugação } \\
\hline $\begin{array}{l}\text { V final do radical não } \\
\text { flexionado }\end{array}$ & \multicolumn{1}{|c|}{ Razão O/E } \\
\hline $\mathrm{e}$ & 2.499014 \\
\hline $\mathrm{o}$ & 1.03714 \\
\hline $\mathrm{a}$ & 0.602566 \\
\hline
\end{tabular}

Tabela 6 - Frequiência relativa da vogal final do radical não flexionado nos verbos da segunda conjugação no MiniDicionário Aurélio.

Na terceira conjugação, a harmonia não implica identidade entre a vogal final do radical não flexionado e a vogal temática [i]. Há outros finais que apresentam alguma concordância com o tema, seja em altura ([u]), seja em posição da língua ([e]). 


\begin{tabular}{|l|r|}
\hline \multicolumn{2}{|c|}{$3^{\mathrm{a}}$ Conjugação } \\
\hline $\begin{array}{l}\mathrm{V} \text { final do radical não } \\
\text { flexionado }\end{array}$ & $\mathrm{O} / \mathrm{E}$ \\
\hline $\mathrm{u}$ & 2.186432 \\
\hline $\mathrm{i}$ & 0.973645 \\
\hline $\mathrm{e}$ & 0.973506 \\
\hline ai & 0.790078 \\
\hline
\end{tabular}

Tabela 7 - Freqüência relativa da vogal final do radical não flexionado nos verbos da terceira conjugação no MiniDicionário Aurélio.

Logo se percebe que a harmonia de altura introduzida pela morfologia para os radicais não flexionados em [e, o] simplesmente confirma e amplia a tendência, já manifestada nos radicais dessa conjugação, a manter a língua alta nas vogais finais de raiz. Como mostra a Tabela 7 , o conjunto dos radicais não flexionados com final em [i] e [u] é, por si só, bastante significativo. Ao assimilar-lhes as formas rizotônicas em [e] e [o] (e.g., 's[i]go', 'tusso'), a morfologia restringe o final em vogal não-alta às poucos radicais não flexionados em [a] (e.g., 'partir'), na maioria irregulares (e.g., 'advir') ou defectivas (e.g., 'falir').

Finalmente, os compostos de pôr, que não constituem propriamente uma conjugação, mas um paradigma de flexão de uma classe fechada de verbos irregulares, apresentam, $\mathrm{n}$ o radical não flexionado, a mesma tendência à harmonia manifestada nas duas conjugações menos produtivas. Como se observa na segunda e na última linhas da Tabela 4, as vogais [o] e [e] são as favoritas como penúltimas vogais do radical não flexionado nessa classe.

Conclui-se que, no sistema verbal do PB, assim como no sistema nominal, as relações entre vogais são coerentes com a tendência das posições acentuáveis a atrair um abaixamento da mandíbula, só tendendo a contrariá-la nos casos em que os radicais costumam ter um final harmônico independente, ou seja, na segunda e terceira conjugações.

$\mathrm{Na}$ primeira conjugação, os radicais pendem ligeiramente para OCP, provavelmente porque isso, na verdade, realça, por contraste, o caráter baixo da vogal temática, que é a mais acentuável do paradigma. Onde o truncamento do radical desloca a acentuabilidade para a esquerda, isto é, nas formas rizotônicas, a harmonia morfológica entra em cena, criando, para as vogais não-altas, formas que satisfazem à tendência ao abaixamento.

Por outro lado, a direção contrária da harmonia nas duas outras conjugações sugere que a língua cultiva meios de tornar previsível uma vogal acentuável não-baixa, o que também realça a inteligibilidade da posição acentuável. 


\section{CONSIDERAÇÕES FINAIS}

Ficou demonstrado acima que, nos verbos, a restrição que se pode chamar harmonia cria exceções ao abaixamento, fazendo com que temas em vogal média ou alta tendam a ter vogais concordes em altura à esquerda. Essa tendência é mais forte na última vogal do radical não flexionado, mas aplica-se também à penúltima e às demais à esquerda, com probabilidades decrescentes.

Em não-verbos, a harmonia não está morfologizada ou lexicalizada. Mas a fonologia introduz o conhecido processo variável de casos como 'm[e/i]nino', que torna previsíveis, isto é, sujeitas a "harmonia", algumas exceções lexicais ao abaixamento.

$\mathrm{O}$ conjunto desses dados sugere que o PB possui várias estratégias lingüísticas, consistentes entre si, fonológicas ou fonotáticas, para evitar a ininteligibilidade, corroborando a visão de Lindblom (1995) sobre o papel da interação falante-ouvinte na estruturação do léxico e da gramática.

\section{$\overline{\text { REFERENNCIAS }}$}

ALBANO, E. 2001. O gesto e suas bordas: esboço de fonologia acústico-articulatória do português brasileiro. Campinas: Mercado de Letras.

ALBANO, E.; A. Moreira; P. Aquino; A. Silva e R. Kakinohana. 1995. Segment frequency and word structure in Brazilian Portuguese. Proceedings ICPhS 95, vol. 3, pp. 346-349.

ALBANO, E. e A. Moreira. 1996. Archisegment-based letter-to-phone conversion for concatenative synthesis in Portuguese. Proceedings of ICSLP'96, vol. 3, pp. 1708-1711.

CAVACAS, A. A. 1920. A língua portuguesa e sua metafonia. Coimbra: Universidade de Coimbra.

FERREIRA, A. B. H. 1977. Minidicionário Aurélio. Rio de Janeiro: Nova Fronteira.

FRISCH, S. 1996. Similarity and frequency in phonology. Tese de doutorado inédita, Northwestern University.

GAMA ROSSI, A. 1998. Qual é a natureza do acento secundário no português brasileiro? Cadernos Centro Universitário São Camilo, vol. 4(1): 77-92.

GREENBERG, J. 1950. The patterning of root morphemes in semitic. Word, 5: 162-181.

HARRIS, J. 1974. Evidence from Portuguese for the 'Elsewhere Condition' in phonology. Linguistic Inquiry, 5(1): 61-80.

KIPARSKY, P. 1973. 'Elsewhere' in phonology. In: S. Anderson \& P. Kiparsky (eds.). A Festschrift for Morris Halle. New York: Holt.

LEBEN, W. 1973. Suprasegmental phonology. Tese de doutorado inédita, MIT.

LINDBLOM, B. 1995. Modelling speaker-listener interaction. In: Bloothooft, G., V. Hazan, D. Huber e J. Llisterri (orgs.) European Studies in Phonetics and Speech Communication. Utrecht: OTS Publications, 1995, pp. 47-52. 
MATEUS, M. H. 1975. Aspectos da fonologia portuguesa. Lisboa: Centro de Estudos Filológicos.

PIERREHUMBERT, J. 1993. Dissimilarity in the Arabic verbal roots. Proceedings of the North East Linguistics Society, 23: 367-381.

1994. Syllable structure and word structure. In: P. Keating (org.). Phonological structure and phonetic form: Papers in laboratory phonology III. Cambridge: Cambridge University Press, pp. 168190. 